\title{
IL-4 and IL-13 exposure during mucociliary differentiation of bronchial epithelial cells increases antimicrobial activity and expression of antimicrobial peptides
}

Suzanne Zuyderduyn ${ }^{1,3^{*}}$, Dennis K Ninaber ${ }^{1}$, Jasmijn A Schrumpf ${ }^{1}$, Marianne AJA van Sterkenburg ${ }^{1}$, Renate M Verhoosel ${ }^{1}$, Frans A Prins ${ }^{2}$, Sandra van Wetering ${ }^{1,3}$, Klaus F Rabe ${ }^{1}$ and Pieter S Hiemstra ${ }^{1}$

\begin{abstract}
The airway epithelium forms a barrier against infection but also produces antimicrobial peptides (AMPs) and other inflammatory mediators to activate the immune system. It has been shown that in allergic disorders, Th2 cytokines may hamper the antimicrobial activity of the epithelium. However, the presence of Th2 cytokines also affects the composition of the epithelial layer which may alter its function. Therefore, we investigated whether exposure of human primary bronchial epithelial cells (PBEC) to Th2 cytokines during mucociliary differentiation affects expression of the human cathelicidin antimicrobial protein (hCAP18)/LL-37 and human beta defensins (hBD), and antimicrobial activity.

PBEC were cultured at an air-liquid interface (ALI) for two weeks in the presence of various concentrations of IL-4 or IL-13. Changes in differentiation and in expression of various AMPs and the antimicrobial proteinase inhibitors secretory leukocyte protease inhibitor (SLPI) and elafin were investigated as well as antimicrobial activity. IL-4 and IL-13 increased mRNA expression of hCAP18/LL-37 and hBD-2. Dot blot analysis also showed an increase in hCAP18/LL-37 protein in apical washes of IL-4-treated ALI cultures, whereas Western Blot analysis showed expression of a protein of approximately $4.5 \mathrm{kDa}$ in basal medium of IL-4-treated cultures. Using sandwich ELISA we found that also hBD-2 in apical washes was increased by both IL-4 and IL-13. SLPI and elafin levels were not affected by IL-4 or IL-13 at the mRNA or protein level. Apical wash obtained from IL-4- and IL-13-treated cultures displayed increased antimicrobial activity against Pseudomonas aeruginosa compared to medium-treated cultures. In addition, differentiation in the presence of Th2 cytokines resulted in increased MUC5AC production as has been shown previously.

These data suggest that prolonged exposure to Th2 cytokines during mucociliary differentiation contributes to antimicrobial defence by increasing the expression and release of selected antimicrobial peptides and mucus.
\end{abstract}

Keywords: human lung, cell differentiation, allergy, inflammation

\section{Background}

The airway epithelium is a pseudostratified columnar epithelium containing basal, secretory and ciliated cells. This layer constantly regenerates through migration, proliferation and differentiation of epithelial cells to form a barrier to protect against inhaled pathogens. In

\footnotetext{
* Correspondence: s.zuyderduyn@lumc.nl

'Department of Pulmonology, Leiden University Medical Center, Leiden, The Netherlands

Full list of author information is available at the end of the article

addition to its barrier function, the epithelium provides mucociliary clearance and releases a variety of mediators such as antimicrobial peptides (AMPs; e.g. the human cathelicidin LL-37 and human beta-defensins [hBD]) and cytokines like the chemokine CXCL8 (interleukin [IL]-8). These mediators initiate and regulate the inflammatory response by inducing recruitment of phagocytes such as neutrophils and monocytes. Due to the influx of these cells and their released compounds local tissue injury occurs. To counteract this injury, the airway 
epithelium secretes serine proteinase inhibitors such as secretory leukocyte proteinase inhibitor (SLPI) and elafin $[1,2]$, which also display antimicrobial activity in vitro against bacteria, fungi and certain viruses (e.g. HIV) [3-6].

Th2 cytokines are expressed in the airways of asthmatics $[7,8]$. Various studies including our own [9] have indicated that Th2 cytokines are able to influence the phenotype of the airway epithelium. Animal models have shown that Th2 cytokines such as IL-13 induce goblet cell hyperplasia [10] and in vitro studies of epithelial cell cultures have shown that the presence of IL-13 during mucociliary differentiation increases goblet cell hyperplasia [11], increases mRNA expression of mucins, decreases mRNA expression of ciliated cell markers FOXJ1, tektin and the novel marker ciliated bronchial epithelial-1 (CBE-1) [12], and increases MUC5AC protein expression [13]. Likewise, it was shown that also IL-4 can drive differentiation of cultured human airway epithelial cells towards a mucus hypersecretory phenotype [13].

We have previously shown that differentiation of airway epithelium markedly affects its function as squamous differentiation of PBEC results in release of more eotaxin-2/CCL24, whereas mucociliary differentiated PBEC (due to the presence of high concentrations of retinoic acid) release more eotaxin-3/CCL26 [9]. In that study [9], we have also shown that presence of IL-4 (or IL-13 to a lesser extent) during the differentiation phase resulted in increased expression of these eotaxins, as well as in an altered epithelial layer.

Antimicrobial defence is thought to be reduced in Th2 driven diseases such as asthma and atopic dermatitis (AD). Studies in atopic dermatitis (AD) patients have shown that the expression of antimicrobial peptides (LL-37, hBD-2 and -3) and proteinase inhibitors (SLPI and elafin) in skin is reduced compared to psoriatic skin. This could explain the increased susceptibility of AD patients to skin infection $[14,15]$. Since AD is a Th2 driven disease, these data suggest that the Th2 cytokine milieu may be detrimental for the antimicrobial defence provided by epithelial cells. Indeed, in cultured keratinocytes, IL- 4 and IL-13 reduce the TNF- $\alpha /$ IFN- $\gamma$-induced hBD-2 and hBD-3 expression [16]. In addition, IL-13 was shown to reduce LL-37 expression in keratinocytes [17]. Not only in skin, but also in the airways Th2 cytokines may affect antimicrobial defence both in vitro and in vivo [18]. First, in cell culture experiments Th2 cytokines reduced the ability of differentiated human bronchial epithelial cells to clear Pseudomonas aeruginosa and the associated increase in hBD-2 mRNA expression. Second, inducing allergic airways inflammation in mice resulted in decreased pulmonary clearance of $P$. aeruginosa and a decrease in CRAMP, the murine homologue of hCAP18/LL-37, in lung lavage fluid [18].
In asthma the constantly regenerating epithelium is exposed to Th2 cytokines during differentiation rather than after differentiation, which leads to goblet cell hyperplasia and increased mucus production, but may also affect other functions of the epithelial layer such as antimicrobial defence. Therefore, in the present study we investigated the effect of presence of Th2 cytokines during mucociliary differentiation on host defence, in particular expression of the antimicrobial peptides LL37 , hBD-2, and -3 , and the antimicrobial proteinase inhibitors SLPI and elafin. In addition, we investigated effects of Th2 cytokine-induced differentiation on morphology and antimicrobial activity of our cultures.

\section{Materials and methods}

\section{Culture of human airway epithelial cells}

Primary bronchial epithelial cells (PBEC) were obtained from anonymized tumour-free lung tissue obtained at lung resection surgery for lung cancer by enzymatic digestion as described previously [19]. Cells from passage 2 were cultured at an air- liquid interface as described previously [9]. In short, cultures were grown submerged for 4-7 days until they reached confluence, after which they were cultured at an air-liquid interface (ALI) for another 2 weeks in medium containing a high concentration of retinoic acid $(15 \mathrm{ng} / \mathrm{ml}$; Lonza, Breda, The Netherlands) to induce mucociliary differentiation. IL-4 or IL-13 (Peprotech, Rocky Hill, NJ) was added during these two weeks of culture at the ALI (see Figure 1). Mucociliary differentiation was usually observed between day 7 and 10 after exposure to air-liquid interface. ALI cultures were maintained for 14 days at $37^{\circ} \mathrm{C}$ in a humidified atmosphere of $5 \% \mathrm{CO}_{2}$. The apical side of the epithelial layers was washed with warm PBS three times a week; medium and stimuli were refreshed at the same time. At the end of the 14-day ALI culture period (48 hours after the last addition of stimulus), basal medium (BM) was harvested and frozen until further use. The apical side of the epithelial cultures was incubated with $100 \mu \mathrm{l}$ of PBS containing $1 \% \mathrm{~N}$-Acetyl-L-cysteine (Sigma-Aldrich) for 15 minutes at room temperature to dissolve mucus threads; this apical wash (AW) was frozen until further use.

\section{RNA isolation, reverse transcription and polymerase chain} reaction

RNA was isolated at the end of the 14-day ALI culture using the Qiagen RNeasy Minikit (Qiagen, Valencia, CA) in combination with the Qiagen RNase-Free DNase Set (Qiagen, Valencia, CA); an additional DNAseI treatment was performed to remove residual chromosomal DNA. Subsequently, RNA was cleaned using a tenth volume 3 M Sodium Acetate (pH 5.2), 2 volumes ice cold ethanol absolute and precipitation overnight at $-20^{\circ} \mathrm{C}$. The RNA 
concentration and purity were determined by measuring optical density measurements using the NanoDrop ND-1000 UV-Vis Spectrophotometer (Nanodrop Technologies, Wilmington, DE). Reverse transcription of $500 \mathrm{ng}$ of total RNA was performed using $200 \mathrm{U}$ of Moloney murine leukemia virus reverse transcriptase (Invitrogen); $0.5 \mathrm{mM}$ of dATP, dCTP, dGTP, dTTP (Invitrogen); $0.5 \mu \mathrm{g}$ of oligo $(\mathrm{dT})_{15}$ primer (Promega, Madison, WI); RNasin RNase inhibitor $40 \mathrm{U}$ (Promega); $10 \mathrm{mM}$ dithiothreitol (Invitrogen); $50 \mathrm{mM}$ Tris- $\mathrm{HCl}$ ( $\mathrm{pH} 8.3$ ); $75 \mathrm{mM} \mathrm{KCl}$; and $3.0 \mathrm{mM} \mathrm{MgCl}$ in a total volume of $20 \mu \mathrm{l}$.

PCR was performed at $95^{\circ} \mathrm{C}$ for 4 minutes followed by 25 or 35 cycles 15 seconds denaturing, 15 seconds annealing and 30 seconds amplification using 0.5 pmol gene specific primers (table 1); nucleotide mix (Invitrogen, Breda, The Netherlands) in a final concentration of $0.08 \mathrm{mM}$ each; $1 \mathrm{U}$ of GoTaq Flexi DNA polymerase (Promega, Madison, WI); $5 \mu \mathrm{l}$ of $5 \times$ Green GoTaq Flexi reaction buffer (Promega) and different concentrations of $\mathrm{MgCl}_{2}$ in a final volume of $25 \mu \mathrm{l}$. $\beta$-actin was used as a reference gene. Products were visualised using a 1.5\% agarose gel containing ethidium bromide.

\section{Quantitative real time Polymerase Chain Reaction}

Quantitative real time PCR was performed on a MyiQ Single-Color Real-Time PCR detection system with IQ5 software (Bio-Rad Laboratories, Veenendaal, The Netherlands) using IQ SYBR Green supermix containing
$3 \mathrm{mM} \mathrm{MgCl}_{2}$ (Bio-Rad) and gene specific primers (table 2). Samples were analysed in triplicate and each PCR included a no-template control and a standard curve in duplicate, made from a sample containing the appropriate cDNA. PCR was performed at $95^{\circ} \mathrm{C}$ for 4 minutes followed by 40 cycles of 15 seconds denaturing, 15 seconds annealing and 30 seconds amplification; fluorescence was measured after each amplification step. A melt curve analysis was performed to determine the primer specificity and the absence of primer dimers. Bio-Rad IQ5 software was used to calculate relative mRNA quantity using the relative standard curve method and to normalize the expression of the genes of interest to both reference genes (GAPDH and $\beta$-actin).

\section{MUC5AC and hCAP18/LL-37 dot blot}

To determine whether MUC5AC protein and hCAP18/ LL-37 protein were released by ALI cultures, apical washes of the cultures were diluted and spotted on a methanolpreincubated polyvinylidene-difluoride (PVDF)-membrane using a Bio-Dot Microfiltration apparatus (Bio-Rad). For MUC5AC, non-specific binding sites were blocked with PBS/5\% w/v skim milk (Fluka, Buchs, Switzerland) overnight at $4^{\circ} \mathrm{C}$, and subsequently the membrane was incubated with $2 \mu \mathrm{g} / \mathrm{ml}$ of mouse-anti-MUC5AC (clone 45M1; Labvision Neomarkers, Fremont, CA) in PBS/5\% (w/v) skim milk for $1 \mathrm{~h}$ at room temperature. For hCAP18/ LL-37, a similar protocol was used. After spotting the 
Table 1 Primers used for RT-PCR

\begin{tabular}{|c|c|c|c|c|}
\hline Name & Primer sequence & Melting temperature $\left({ }^{\circ} \mathrm{C}\right)$ & $\mathrm{MgCl}_{2}(\mathrm{mM})$ & Product size (base pairs) \\
\hline$\beta$-actin & $\begin{array}{l}\text { F:GGAAGGCTGGAAGAGTGC } \\
\text { R:CTACAATGAGCTGCGTGTGG }\end{array}$ & 56 & 2 & 528 \\
\hline hCAP18/LL-37 & $\begin{array}{l}\text { F:GGCTCCTTTGACATCAGTT } \\
\text { R:CTGTCCTGGGTACAAGATTCC }\end{array}$ & 55 & 2.5 & 150 \\
\hline hBD-2 & $\begin{array}{l}\text { F:ATCAGCCATGAGGGTCTTG } \\
\text { R:GCAGCATTITGTTCCAGG }\end{array}$ & 62 & 2 & 190 \\
\hline hBD-3 & $\begin{array}{l}\text { F:AGCCTAGCAGCTATGAGGATC } \\
\text { R:CTTCGGCAGCATITTGCGCCA }\end{array}$ & 62 & 2 & 206 \\
\hline MUC5AC & $\begin{array}{l}\text { F:ATTाTाTCCCCACTCCTGATG } \\
\text { R:AAGACAACCCACTCCCAACC }\end{array}$ & 58 & 2 & 146 \\
\hline MUC2 & $\begin{array}{l}\text { F:GACGCACTGTATCATCAAACG } \\
\text { R:AGGATGGTCGTGTTGATGCG }\end{array}$ & 58 & 2 & 409 \\
\hline CBE-1 & $\begin{array}{l}\text { F:GGTCAGAGCTTGAGGTAGCATGTG } \\
\text { R:GAGTTGTAACAGCACACTGCATTC }\end{array}$ & 60 & 3 & 395 \\
\hline Tektin & $\begin{array}{l}\text { F:AGCTGGCTGATCATCTGGCCAAG } \\
\text { R:GGATTTCCTCATCTGCATACACAG }\end{array}$ & 60 & 2 & 358 \\
\hline
\end{tabular}

samples, non-specific binding sites were blocked using $\mathrm{PBS} / 5 \%(\mathrm{v} / \mathrm{v})$ heat-inactivated newborn calf serum (NBCS; Gibco, Grand Island, NY)/5\% (v/v) skim milk (Fluka, Buchs, Switzerland) for $2 \mathrm{~h}$ at room temperature. Subsequently, the membrane was incubated overnight at $4^{\circ} \mathrm{C}$ with monoclonal anti-LL-37 antibody $1.1 \mathrm{C} 12(2 \mu \mathrm{g} / \mathrm{ml})$ in $\mathrm{PBS} / 5 \%(\mathrm{v} / \mathrm{v})$ heat-inactivated NBCS/5\% (w/v) skim milk. A HRP-conjugated goat-anti-mouse IgG (subclasses 1+2a $+2 b+3 a n t i b o d y$ ) (Jackson ImmunoResearch Laboratory, Bar Harbor, ME) was used as a secondary antibody for MUC5AC and a HRP-conjugated goat-anti-mouse Ig antibody (Dako) for the LL-37 dot blot and detected using ECL Western Blotting substrate (Pierce, Rockford, IL). Densitometry was performed using Totallab image analysis software (Nonlinear Dynamics, Newcastle upon Tyne, UK).

\section{hCAP18/LL-37 Western Blot}

Basal media, apical washes and cell lysates were harvested after 14 days of culture. Four $\mathrm{ml}$ of BM and 200 $\mu \mathrm{l}$ of AW were pooled per stimulus, concentrated using Oasis HLB 1cc extraction cartridges (Waters Chromotography, Etten-Leur, The Netherlands), and subjected to
SDS-PAGE on a $16.5 \%$ Tris-Tricine gel as described earlier [20]. After protein separation, proteins were blotted onto PVDF for $1.5 \mathrm{~h}$ and subsequently blocked with $\mathrm{PBS} / 5 \%(\mathrm{v} / \mathrm{v})$ heat-inactivated NBCS/5\% (w/v) skim milk. The monoclonal mouse anti-hCAP18/LL-37 clone 1.1.C12 (diluted 1:1000) in combination with goat-antimouse-HRP (Dako; diluted 1:1000) or a polyclonal rabbit-anti-hCAP18/LL-37 (Innovagen; diluted 1:200) together with swine-anti-rabbit-HRP (Dako: diluted $1: 1000)$ in combination with ECL were used to detect hCAP18/LL-37. Synthetic LL-37 (0.5 ng) and a nasal secretion sample were used as positive controls for LL37 and hCAP18 respectively. Kaleidoscope polypeptide standard (Bio-Rad) was used as a molecular weight marker.

Measurement of protein levels of antimicrobial peptides hCAP18/LL-37, hBD-2, hBD-3 and the antimicrobial protease inhibitors SLPI and elafin

All proteins were measured using well-established sandwich ELISAs. hCAP18/LL-37 and elafin/SKALP levels were measured using commercially available kits (Hycult

Table 2 Primers used for quantitative real time PCR

\begin{tabular}{|c|c|c|c|}
\hline Name & Primer Sequence & Melting Temperature $\left({ }^{\circ} \mathrm{C}\right)$ & Product size (base pairs) \\
\hline$\beta$-actin & $\begin{array}{l}\text { F: TGCGTGACATTAAGGAGAAG } \\
\text { R: TGAAGGTAGTTCGTGGATG }\end{array}$ & 63 & 213 \\
\hline GAPDH & $\begin{array}{l}\text { F: TTCCAGGAGCGAGATCCCT } \\
\text { R: CACCCATGACGAACATGGG }\end{array}$ & 62 & 259 \\
\hline hCAP18/LL-37 & $\begin{array}{l}\text { F: TCATTG CCCAGGTCCTCAG } \\
\text { R: TCCCCATACACCGCTTCAC }\end{array}$ & 64.3 & 249 \\
\hline MUC5AC & $\begin{array}{l}\text { F: CCTTCGACGGACAGAGCTAC } \\
\text { R: TCTCGGTGACAACACGAAAG }\end{array}$ & 63.5 & 111 \\
\hline SLPI & $\begin{array}{l}\text { F: CCAGGGAAGAAGAGATGTTG } \\
\text { R: CCTCCATATGGCAGGAATC }\end{array}$ & 61 & 226 \\
\hline Elafin & $\begin{array}{l}\text { F: CCGCTGCTTGAAAGATACTG } \\
\text { R: GAATGGGAGGAAGAATGGAC }\end{array}$ & 59.2 & 177 \\
\hline
\end{tabular}


biotechnology, Uden, The Netherlands). hBD-3 levels were measured using the human beta-defensin-3 ELISA kit (Phoenix Pharmaceuticals, Karlsruhe, Germany). SLPI release was measured using a sandwich ELISA as described earlier [21], and hBD-2 levels were measured as previously described [22].

\section{Antimicrobial assay}

The antimicrobial assay was adapted from Diamond et al. [23]. ALI cultures of PBEC were established. Two days prior to harvesting, medium was replaced by antibiotics-free growth medium and the last stimulation with IL-4 and IL-13 was performed. Apical wash was harvested using $70 \mu \mathrm{l}$ of $10 \mathrm{mM}$ sodium phosphate buffer $\mathrm{pH} 7.4$ and stored at $-20^{\circ} \mathrm{C} .250$ colony forming units (CFU) of mid-log phase Pseudomonas aeruginosa strain PAO1 (BAA-47, American Type Culture Collection, Rockville, MD, USA) were inoculated into AW (42.5 $\mu$ l bacteria added to $7.5 \mu \mathrm{l}$ of AW) and left shaking for 3 hours at $37^{\circ} \mathrm{C}$. The number of $\mathrm{CFU} / \mathrm{ml}$ was determined by plating serial dilutions on LB agar plates; colonies were counted after overnight incubation at $37^{\circ} \mathrm{C}$.

\section{Morphology of air-liquid interface cultures}

The morphology of the cultures was assessed using light microscopy and transmission electron microscopy (TEM). At the end of the cultures, cells were fixed using a solution of $1 \%$ paraformaldehyde (Merck)/1.5\% glutaraldehyde (BDH Laboratory Supplies, Poole, UK)/0.1 M sodium cacodylate buffer ( $\mathrm{pH} 7.4$, Merck) for $20 \mathrm{~min}-$ utes at room temperature, washed in cacodylate buffer, post-fixed using $1 \%$ osmium tetraoxide $(\mathrm{BDH})$ in $0.1 \mathrm{M}$ sodium cacodylate buffer for 10 minutes, rinsed in distilled $\mathrm{H}_{2} \mathrm{O}$ and dehydrated in ethanol. Subsequently the filters were embedded in 1:1 epon (PolyBed, Polysciences, Germany)/ethanol absolute for at least one hour, followed by a 2:1 epon/ethanol absolute for another hour. Filters were then embedded in pure epon in a mould and the epon was allowed to polymerize at $60^{\circ} \mathrm{C}$ for at least 24 hours. One micron sections were stained using 1\% Toluidin Blue and viewed with a Leica $\mathrm{DM} / \mathrm{RB}$ microscope and sequential ultra-thin sections were examined in a JEOL JEM-1011 electron microscope with digital photography using a MegaView III camera.

\section{Immunofluorescence staining of MUC5AC in air-liquid interface cultures}

ALI cultures were fixed in $1 \% \mathrm{w} / \mathrm{v}$ paraformaldehyde (Merck) in PBS. Subsequently, the filters were blocked with PBS/1\% w/v BSA $/ 0.05 \% \mathrm{v} / \mathrm{v}$ Tween-20 for $30 \mathrm{~min}$ utes at $4^{\circ} \mathrm{C}$, washed with $\mathrm{PBS}$ and incubated with methanol for 20 minutes at $4^{\circ} \mathrm{C}$. After washing with PBS, primary antibodies were incubated overnight at $4^{\circ}$
C (mouse-anti-MUC5AC clone $45 \mathrm{M} 1$ at $0.2 \mu \mathrm{g} / \mathrm{ml}$ ); followed by washing with PBS and incubation with Alexa Fluor-labeled secondary antibodies (goat-anti-mouse IgG $(\mathrm{H}+\mathrm{L})$-Alexa Fluor 488 for $2 \mathrm{~h}$ at $4^{\circ} \mathrm{C}$. After washing with PBS, filters were mounted on glass slides, covered with Vectashield (Vector Laboratories, Burlingame, CA) and a coverglass. Pictures were taken using a confocal Laser Scanning Microscope (Zeiss LSM510; Zeiss, Jena, Germany).

\section{Statistics}

Results are expressed as mean \pm SEM. Data were analyzed using the non-parametric Wilcoxon signed ranks test. Differences at $\mathrm{p}$ values smaller than 0.05 were considered statistically significant.

\section{Results}

Two-week exposure of differentiating bronchial epithelial cells to IL-4 or IL-13 enhances hCAP18/LL-37 and hBD-2 mRNA expression as well as hCAP18/LL-37 protein release To study how exposure to IL-4 or IL-13 during differentiation of bronchial epithelial cells affects expression of antimicrobial peptides, we exposed PBEC that were cultured at the ALI to various concentrations of these cytokines for 14 days to induce differentiation (see Figure 1). Both IL-4 and IL-13 enhanced mRNA expression of hCAP18/LL-37 and hBD-2 in ALI cultures using cells from five different donors (Figure 2A). hBD-3 mRNA expression was very low in the ALI cultures (data not shown). IL-4 and IL-13 increased hCAP18/LL-37 protein release as assessed by dot blot analysis of apical washes obtained from two ALI cultures using cells from the same two donors (Figure 2B). Using a sandwich ELISA for hCAP18/LL-37 with a lower detection limit of $100 \mathrm{pg} / \mathrm{ml}$, we were not able to detect the protein in apical wash or basal medium. However, using SDSPAGE and Western Blot analysis, we show that concentrated basal medium of ALI cultures treated with IL-4 contain a protein of approximately $4.5 \mathrm{kDa}$ (Figure $2 \mathrm{C}$ ), suggesting that hCAP18 is cleaved into a smaller fragment which could either be LL-37 or other peptides known to be cleaved from hCAP18 [24]. hBD-2 protein level in apical washes was increased by both IL-4 and IL-13 (Figure 2D), whereas in basal medium it was not. hBD-3 protein release into apical washes as measured by ELISA was variable: it was undetectable in cultures from two out of six donors; IL-4 induced hBD-3 protein release in cultures of two donors, whereas it decreased hBD-3 protein release in cultures of two other donors (data not shown). We did not assess effects of IL-13 on hBD-3 expression.

These data show that exposure to Th2 cytokines during differentiation increases the mRNA expression and protein release of hCAP18/LL-37 and hBD-2 by 
A

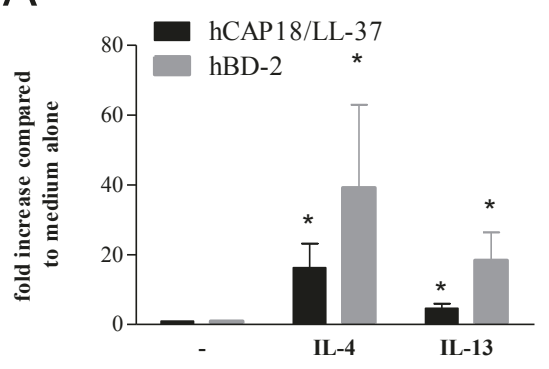

C
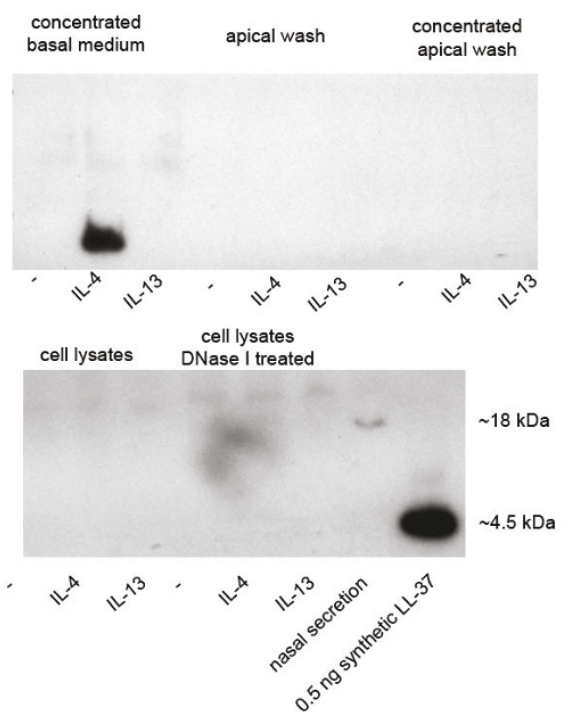

B
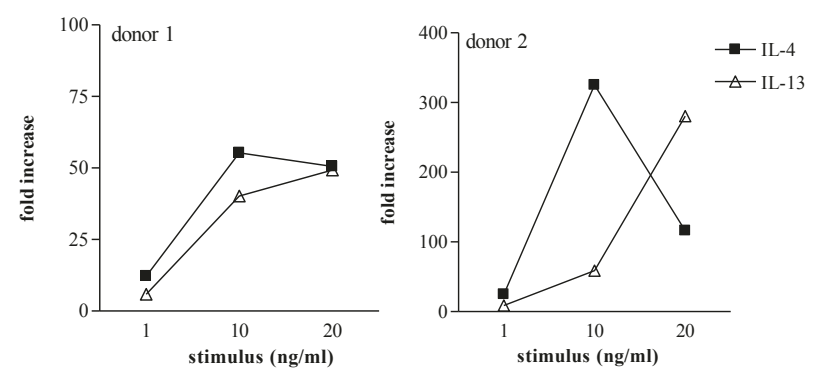

D

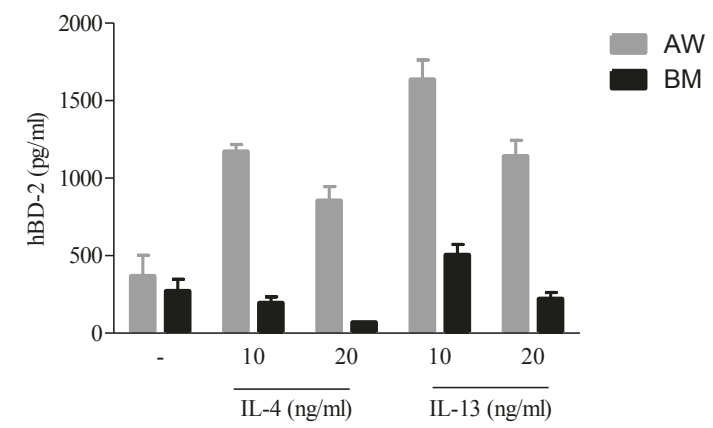

E
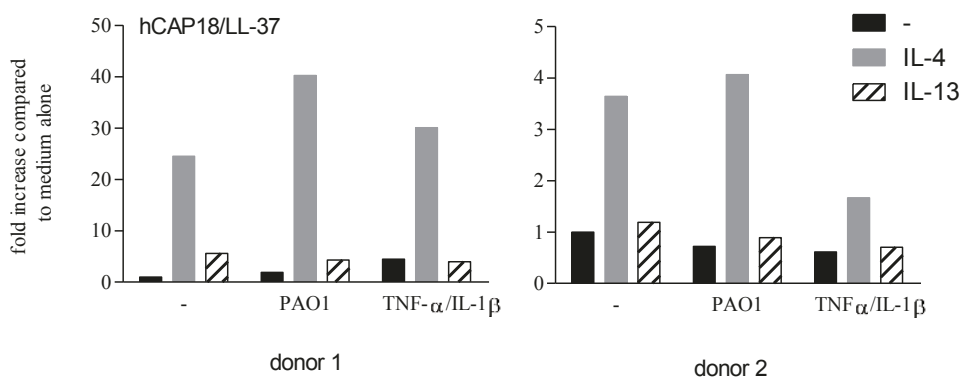

Figure 2 Two week exposure to IL-4 or IL-13 increases the expression of the antimicrobial peptides hCAP18/LL-37 and hBD-2. PBEC from various donors were cultured at an ALI for two weeks in the presence of various concentrations of IL-4 or IL-13. (A) Quantitative real time PCR of LL-37 and hBD-2. Data were normalized for expression against two reference genes ( $\beta$-actin and GAPDH). Data are represented as mean \pm SEM of fold increase compared to medium alone for five different donors. ${ }^{*} p<0.05$ Wilcoxon signed ranks test. (B) Densitometry results (fold increase compared to medium alone) from the dot blot analysis of hCAP18/LL-37 expression in apical washes of ALI cultures using cells from two donors. (C) Western Blot of LL-37 in cultures treated with medium alone (-), IL-4 (20 ng/ml), or IL-13 (20 ng/ml). From left to right: basal medium concentrated using Oasis cartridges, apical washes, apical washes concentrated using cartridges, cell lysates, cell lysates treated with DNasel obtained from one culture, and a nasal secretion sample and $0.5 \mathrm{ng}$ of synthetic LL-37 as controls. Similar results were obtained in basal medium from another donor using another antibody specific for hCAP18/LL-37. (D) ELISA for hBD-2 on apical washes and basal medium; mean \pm SEM of $n=3$ and $n=4$ experiments, respectively. (E) Two ALI cultures that were differentiated in the absence or presence of IL-4 or IL-13 for two weeks were subsequently stimulated with $10^{8}$ CFU heat-inactivated $P$. aeruginosa PAO1 or with a combination of TNF- $\alpha$ and IL-1 $1 \beta$ (both at $20 \mathrm{ng} / \mathrm{ml}$ ) for $24 \mathrm{~h}$. Quantitative real time PCR of hCAP18/LL-37. Data were normalized for expression against two reference genes ( $\beta$-actin and GAPDH). Two separate experiments are shown; data are represented as fold increase compared to medium alone. 
bronchial epithelial cells, but has an inconclusive effect on hBD-3 expression. In addition, our data show that hCAP18 is released into the basal medium and is cleaved into a smaller fragment of approximately 4.5 $\mathrm{kDa}$ containing an epitope recognized by LL-37 antibodies.

Previously it was shown that pro-inflammatory stimuli and bacteria increase hBD-2 expression in epithelial cells, and the induction was inhibited when Th2 cytokines were added during stimulation. We have now also investigated whether differentiation in the presence of IL- 4 or IL-13 affected bacteria- or TNF- $\alpha /$ IL- $1 \beta$-induced AMP expression. In two experiments we observed that in ALI cultures differentiated in medium alone, PAO1 and TNF- $\alpha / \mathrm{IL}-1 \beta$ induced a marked increase in hBD-2 expression, which was reduced (to a varying degree in two donors), when cells were differentiated in the presence of IL-4, indeed suggesting that Th2 cytokines may inhibit hBD-2 expression (data not shown). However, hCAP18/LL-37 expression was increased to a greater extent by IL-4 and IL-13 differentiation than by the proinflammatory stimuli suggesting that differentiation of the epithelium is important for induction of hCAP18/ LL-37 rather than pro-inflammatory stimuli (Figure 2E).
Two-week exposure of differentiating epithelial cells to IL-4 or IL-13 does not affect the expression of SLPI and elafin protein release

To study the effect of presence of Th2 cytokines during differentiation on release of the antimicrobial proteinase inhibitors SLPI and elafin, PBEC were cultured at an ALI for 14 days in the absence or presence of various concentrations of IL-4 and IL-13 during differentiation. Basal medium and apical washes were harvested at the end of the culture. No significant differences in SLPI or elafin release in basal medium (BM) or apical wash (AW) were found when IL-4- and IL-13-treated cultures were compared to medium-treated cultures (Figure 3A). In addition, no effects on mRNA expression were found (Figure 3B). These data show that the antimicrobial protease inhibitors SLPI and elafin are not increased during IL-4- or IL-13-induced differentiation of ALI cultures.

\section{Two-week exposure of differentiating epithelial cells to IL-4 or IL-13 enhances antimicrobial activity in apical wash}

To assess whether IL-4- and IL-13-treated ALI cultures displayed antimicrobial activity, we harvested apical wash and measured antimicrobial activity. Growth of

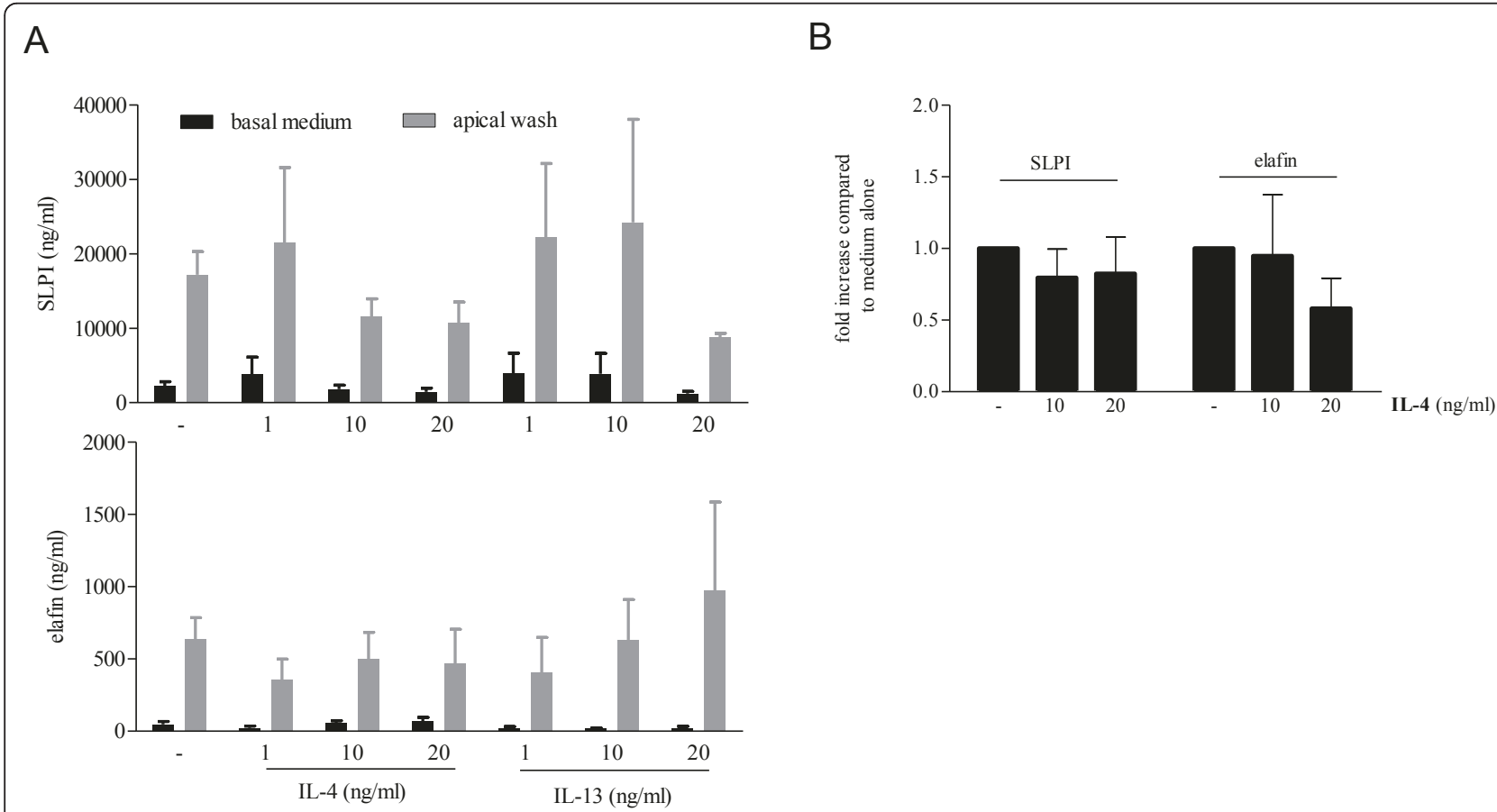

Figure 3 Two week exposure to IL-4 or IL-13 does not affect the release of the antimicrobial proteinase inhibitors SLPI or elafin. PBEC from six different donors were cultured at an ALI for 14 days in the presence of 1, 10 or $20 \mathrm{ng} / \mathrm{ml}$ of IL-4 or IL-13. (A) Basal medium (black bars) and apical washes (gray bars) were harvested and analyzed for SLPI (upper panel) and elafin (lower panel) protein levels using sandwich ELISA. Data are presented as mean \pm SEM from experiments performed in duplicate $(-n=8 ; I L-41 \mathrm{ng} / \mathrm{ml} n=3 ; \mathrm{IL}-410 \mathrm{ng} / \mathrm{ml} \mathrm{n=8;} \mathrm{IL-4} 20 \mathrm{ng} / \mathrm{ml} \mathrm{n}$ $=7 ; \mathrm{IL}-131 \mathrm{ng} / \mathrm{ml} \mathrm{n}=3 ; \mathrm{IL}-1310 \mathrm{ng} / \mathrm{ml} \mathrm{n}=3 ; \mathrm{IL}-1320 \mathrm{ng} / \mathrm{ml} \mathrm{n}=2$ ). (B) Quantitative real time PCR for SLPI and elafin mRNA expression. Data are mean \pm SEM of fold increase compared to medium alone for 4 independent experiments. Data were normalized for expression against two reference genes ( $\beta$-actin and GAPDH). 
Pseudomonas aeruginosa was inhibited by apical wash obtained from six separate ALI cultures treated with IL4 or IL-13 (Figure 4). When compared to phosphate buffer alone, medium-treated ALI cultures also exhibited some antimicrobial activity (data not shown). We did not find any antimicrobial activity in basal medium of the IL-4- and IL-13-treated cultures.

\section{Two-week exposure of differentiating epithelial cells to} IL-4 affects the morphology of the epithelial layer

As it was previously shown that IL-4 and IL-13 affect bronchial epithelial cell differentiation [13], we investigated morphology and markers of ciliated and goblet cells. Also in our cultures, differentiation in the presence of IL-4 affects morphology; a thickened layer containing more goblet cells is formed (Figure $5 \mathrm{C}$ ). An increase in MUC5AC mRNA expression was observed in IL-4- and IL-13-treated cultures using quantitative real time PCR (Figure 5B), whereas a reduction of FoxJ1 mRNA expression was found in 5 out of 6 donors (data not shown). Reverse transcriptase PCR showed that IL-4 also reduced mRNA expression of tektin and CBE-1 (other markers of ciliated epithelial cells), whereas expression of MUC2 mRNA was enhanced (Figure 5A). MUC5B mRNA expression was not altered by IL-4. Using dot blot analysis, we observed that IL-4 slightly increased MUC5AC protein release in five out of six experiments using cells from four different donors (Figure 5D). These data confirm previous findings [10-13] by showing that also in our cultures, two-week exposure to IL-4 during differentiation alters the morphology of bronchial epithelial cells, increases the production of MUC5AC, and decreases expression of markers of ciliated cells.

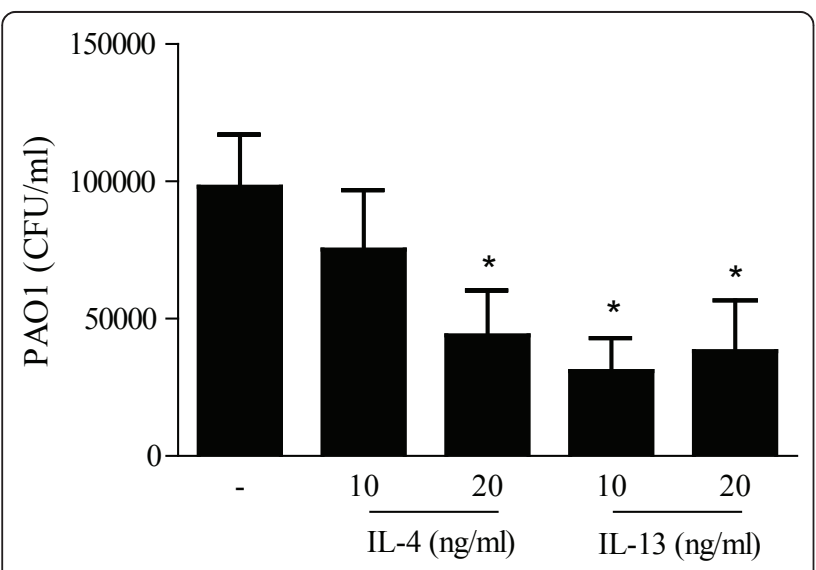

Figure 4 Two week exposure to IL-4 or IL-13 enhances antimicrobial activity. Apical wash was harvested using a $10 \mathrm{mM}$ sodium phosphate buffer pH 7.4 and added to 250 colony forming units (CFU) of log phase $P$. aeruginosa PAO1 for $3 \mathrm{~h}$. Bacteria were plated to assess number of CFU. Data represent mean CFU/ml \pm SEM using apical washes obtained from six different donors.
Exposure of already differentiated bronchial epithelial cells to IL-4 does not affect hCAP18/LL-37 expression Next we assessed whether IL-4 also increases hCAP18/ LL-37 expression in already differentiated epithelial layers. To this end, we differentiated bronchial epithelial cells at an ALI for 14 days using retinoic acid to induce mucociliary differentiation; subsequently we stimulated the cells with 10 or $20 \mathrm{ng} / \mathrm{ml}$ of IL-4 for 48 hours and assessed mRNA expression for hCAP18/LL-37, SLPI and elafin. In this model, IL-4 did not induce mRNA expression of hCAP18/LL-37 ( $\mathrm{n}=2$, data not shown). These data suggest that the altered differentiation (increase in goblet cells) induced by IL-4 and IL-13 is responsible for the increase in hCAP18/LL-37.

\section{Discussion}

In this study, we investigated whether the presence of Th2 cytokines during mucociliary differentiation of bronchial epithelial cell cultures affects antimicrobial defence. Our results show that two-week exposure of differentiating epithelial cells to the Th2 cytokine IL-4 induces an increase in hCAP18/LL-37 and hBD-2 mRNA and protein expression, whereas levels of the antimicrobial proteinase inhibitors SLPI and elafin were not affected. In addition to IL-4, also exposure to IL-13 during differentiation resulted in an increase of hCAP18/LL-37 and hBD-2 mRNA, as well as increased protein expression in apical washes. However, only in basal medium of IL-4-treated cultures a peptide of approximately $4.5 \mathrm{kDa}$ was detected suggestive of the antimicrobial peptide LL-37. Apical wash obtained from ALI cultures treated with IL-4 or IL-13 exhibited increased antimicrobial activity compared to mediumtreated cultures as shown by increased killing of $P$. aeruginosa PAO1 suggesting that increased expression of LL-37 and hBD-2 contribute to the increased antimicrobial activity.

In line with previous findings $[12,13]$, in our experiments IL-4 and IL-13 exposure increased MUC5AC mRNA expression. Using various concentrations of IL-4 we also showed that MUC5AC protein expression was increased and markers of ciliated cells were decreased, suggesting that goblet cell hyperplasia was induced. As we did not observe effects of IL-4 on AMPs expression when added to already-differentiated cultures, perhaps the IL-4- or IL-13-induced changes in differentiation underlie the observed increased expression of antimicrobial peptides and increased antimicrobial activity. In other models of differentiated epithelia, such as a model of human gingiva [25] and in differentiated colonic epithelium [26], increased expression of hCAP18/LL-37 and $\beta$-defensins has also been shown, and was suggested to be related to the differentiation status. In our study, hCAP18/LL-37 and hBD-2 expression was induced in 


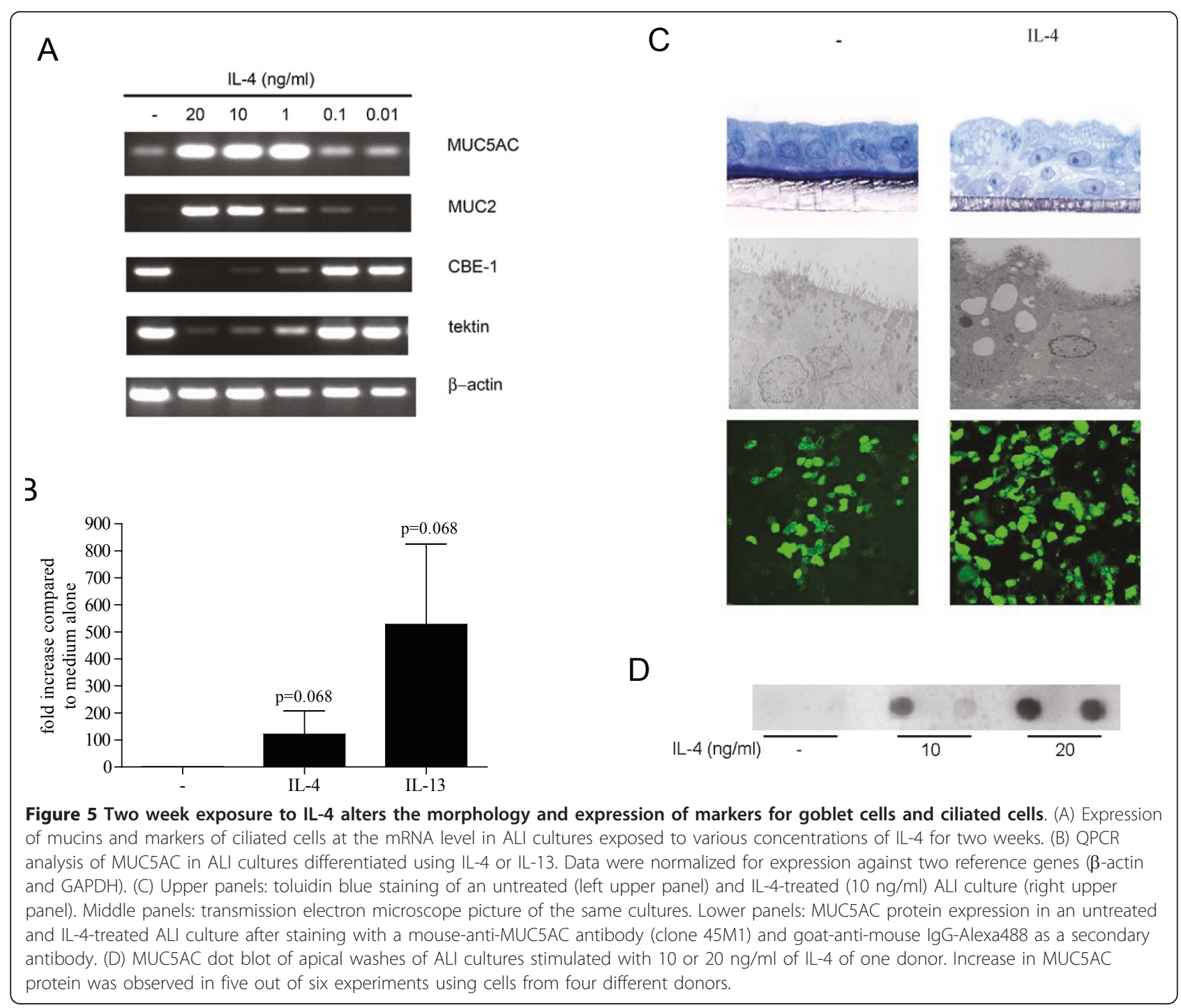

cultures that were differentiated in the presence of IL-4 or IL-13 which resulted in an epithelial layer resembling goblet cell hyperplasia in e.g. asthmatic epithelium. In contrast, short-term ( 48 h) IL- 4 treatment of already fully-differentiated cultures (using retinoic acid) did not affect hCAP18/LL-37 mRNA levels. It has been shown by others that $48 \mathrm{~h}$ stimulation of mucociliary differentiated epithelial layers with IL-4 or IL-13 did not result in increased release of mediators (GM-CSF and TGF$\beta 2)$, contrary to what occurs in submerged cultures [27]. These data are in concordance with our data on the lack of effect of short term stimulation on hCAP18/LL37 expression by mucociliary differentiated epithelial layers. Taken together these data suggest that increased hCAP18/LL-37 and hBD-2 expression in airway epithelial cells is perhaps related to the altered differentiation of the epithelial cell layer. However, we have not yet been able to identify which cell type in our ALI cultures is responsible for the production of the antimicrobial peptides.

In contrast to other studies showing a reduction in PAO1 - or TNF $\alpha / \mathrm{IL}-1 \beta$-induced hBD- 2 expression by Th2 cytokines, we now show that differentiation in the presence of IL-4 or IL-13 increases hCAP18/LL-37 and hBD-2 expression in the absence of bacterial or proinflammatory stimuli. In separate experiments we observed that although IL-4 and IL-13 increase hBD-2 expression in our culture model, also when IL-4- or IL13-differentiated cultures were subsequently stimulated with PAO1 or TNF- $\alpha /$ IL-1 $\beta$, hBD- 2 mRNA induction by these stimuli was slightly reduced. hCAP18/LL-37 expression, however, was not affected by $24 \mathrm{~h}$ stimulation with PAO1 or TNF $\alpha / \mathrm{IL}-1 \beta$ whereas differentiation in the presence of IL- 4 or IL-13 increased the expression. These data suggest that differentiation in the presence of Th2 cytokines alone results in increased 
expression of AMPs, but can also hamper induction of AMP expression by bacterial and other pro-inflammatory stimuli. Whether the same effects exist when Th1 or pro-inflammatory cytokines are also present during differentiation remains the question.

Using an antimicrobial activity assay, we have now shown that presence of IL-4 or IL-13 during differentiation leads to increased antimicrobial activity. Previously it was shown that airway surface fluid has a complex composition of various mediators including many antimicrobial peptides [28], which may additively or synergistically enhance antimicrobial activity. We measured low levels of hBD-2 (1-1.5 ng/ml after IL-4 or IL-13) and were unable to detect LL-37 using a sandwich ELISA with a $100 \mathrm{ng} / \mathrm{ml}$ lower detection limit. It has been reported that $0.16 \mu \mathrm{g} / \mathrm{ml}$ of hBD-2 kills $50 \%$ of $E$. coli [28], whereas clinical isolates of $S$. aureus were very resistant [14]. In addition it was shown $5 \mu \mathrm{g} / \mathrm{ml}$ of hBD-2 was needed to kill $50 \%$ of $P$. aeruginosa (clinical isolate PA-O) [29], whereas $16 \mu \mathrm{g} / \mathrm{ml}$ of synthetic LL-37 was needed to kill P. aeruginosa ATCC 27853 [30]. Since the levels of hBD-2 and LL-37 that we detected were much lower, it is unlikely that the antimicrobial activity of apical washes obtained from IL-4- or IL-13-treated cultures is solely due to the activity of LL-37 or hBD-2 alone. However, it has been shown that low (subinhibitory) concentrations of LL-37, lactoferrin and SLPI synergize with lysozyme to kill E. coli [28]. It has been previously shown that ALI cultures of bronchial epithelial cells express small amounts of lysozyme and lactoferrin [31]. Using IL-9, another Th2 cytokine, in differentiating epithelial cells also results in an increase in goblet cells and lysozyme [32]. In addition, it has been shown that the combination of LL-37 and hBD-2 kills more $S$. aureus than hBD-2 [14]. Therefore, perhaps the increased antimicrobial activity of the apical washes of our IL-4- and IL-13-treated cultures is due to synergistic or additive effects of LL-37 or hBD-2 with lysozyme or other compounds since the expression of both LL37 and hBD-2 is increased in these cultures compared to medium-treated cultures. In the future, neutralizing various AMPs in apical washes may provide an answer to the question which AMPs are responsible for the increased antimicrobial activity of IL-4- and IL-13treated cultures observed.

Our study has some limitations. We were not able to detect hCAP18/LL-37 expression in washes obtained from the apical side of the cultures using a sandwich ELISA and SDS-PAGE followed by Western Blot, whereas this apical wash did display antimicrobial activity. As it is known that LL-37 can bind to mucus and DNA [33,34], perhaps epitopes are masked due to these interactions which leads to the detection problems found in the aforementioned assays. Another possibility is that levels of hCAP18/LL-37 were below the detection limits of our assays. In addition, we were only able to detect hCAP18/LL-37 in the basal medium of IL-4-treated cultures and not in IL-13-treated cultures, whereas both cytokines increased mRNA and protein expression assessed by dot blot analysis. We do not think this is due to the fact that IL-13 is less potent in inducing antimicrobial substances as it was equipotent if not more potent in the antimicrobial assay and the induction of hBD-2 protein release. Since we also did not detect hCAP18/LL-37 in basal medium using a higher amount of IL-13 (100 ng/ml) during differentiation (unpublished data), possibly IL-13 does not induce sufficient secretion of hCAP18/LL-37 to the basal side, but only to the apical side.

Which clinical implications do our results have? The increase in AMP expression after differentiation in the presence of Th2 cytokines may contribute to the first line of defence, which is necessary until inflammatory cells capable of dealing with the microbes are present at the site of invasion. It is known that neutrophils are a potent source of hCAP18/LL-37 and neutrophil defensins, and that these cells probably produce greater amounts of these AMPs than epithelial cells. We have not been able to measure quantifiable amounts of hCAP18/LL-37 using the sandwich ELISA suggesting that very low amounts $(<100 \mathrm{pg} / \mathrm{ml})$ of hCAP18/LL-37 are present in our cultures or that this method is not suitable for detection of this AMP in our cultures. However, as the apical washes of the IL-4- and IL-13-treated cultures displayed increased antimicrobial activity, this confirms that the airway epithelium contributes to the antimicrobial defence. In addition, the increase in hCAP18/LL-37 and hBD-2 may result in increased activation of the adaptive immune response, since it is known that these AMPs can act as chemoattractants for phagocytes and dendritic cells, and LL-37 can affect DC differentiation [35].

In conclusion, differentiation of epithelium in the presence of Th2 cytokines IL-4 and IL-13 results in an altered epithelial layer that not only produces more mucus, but also more hCAP18/LL-37 and hBD-2, and displays increased antimicrobial activity.

\section{Acknowledgements}

This work was supported by an unrestricted research grant from Boehringer Ingelheim Pharma GmbH \& Co. KG, Biberach, Germany. The authors thank David Proud (University of Calgary, Canada) for the generous gift of ELISA reagents to detect $\mathrm{hBD}-2$ release.

\section{Author details}

${ }^{1}$ Department of Pulmonology, Leiden University Medical Center, Leiden, The Netherlands. ${ }^{2}$ Pathology, Leiden University Medical Center, Leiden, The Netherlands. ${ }^{3}$ DCPrime BV, De Boelelaan 1085, 1081 HV, Amsterdam, The Netherlands. 


\section{Authors' contributions}

SZ was involved in conception and design of the study, performing experiments, analyzing and interpreting data and drafted and revised the manuscript. DN and JS performed experiments and were involved in analyzing and interpreting data. MS and RV substantially assisted in performing all of the cell cultures. FP assisted in experiments involving histological and immunofluorescence techniques. SW and KR were involved in conception of the study, and critically revised the manuscript. PH was involved in conception and design of the study, interpretation of data and drafting and revision of the manuscript. All authors have read and approved the manuscript.

\section{Competing interests}

$\mathrm{SZ}$ is sponsored by a research grant from Boehringer Ingelheim Pharma GmbH\&Co. KG, Biberach, Germany. DN, JS, RV, MS, FP and SW have no competing interests. The Department of Pulmonology, and thereby KR as head of the department and PH as staff member, has received grants from AltanaPharma, Amgen, Centocor, Novartis, Bayer, AstraZeneca, Pfizer, MSD, Exhale Therapeutics, Boehringer Ingelheim, Roche and GSK. KR and PH have been consulting, participated in Advisory Board Meetings and received lecture fees from AstraZeneca, Amgen, Boehringer, Centocor, Chiesi Pharmaceuticals, Pfizer, Novartis, AltanaPharma, MSD, and GSK.

\section{Received: 22 April 2010 Accepted: 2 May 2011 Published: 2 May 2011}

\section{References}

1. Van Wetering $S$, van der Linden AC, van Sterkenburg MA, de Boer WI, Kuijpers AL, Schalkwijk J, et al: Regulation of SLPI and elafin release from bronchial epithelial cells by neutrophil defensins. Am J Physiol Lung Cell Mol Physiol 2000, 278:L51-L58.

2. Williams SE, Brown TI, Roghanian A, Sallenave JM: SLPI and elafin: one glove, many fingers. Clin Sci (Lond) 2006, 110:21-35.

3. Hiemstra PS, Maassen RJ, Stolk J, Heinzel-Wieland R, Steffens GJ, Dijkman JH: Antibacterial activity of antileukoprotease. Infect Immun 1996, 64:4520-4524.

4. Simpson AJ, Wallace WA, Marsden ME, Govan JR, Porteous DJ, Haslett C, et al: Adenoviral augmentation of elafin protects the lung against acute injury mediated by activated neutrophils and bacterial infection. J Immunol 2001, 167:1778-1786.

5. Sallenave JM: Antimicrobial activity of antiproteinases. Biochem Soc Trans 2002, 30:111-115.

6. McNeely TB, Shugars DC, Rosendahl M, Tucker C, Eisenberg SP, Wahl SM: Inhibition of human immunodeficiency virus type 1 infectivity by secretory leukocyte protease inhibitor occurs prior to viral reverse transcription. Blood 1997, 90:1141-1149.

7. Del Prete GF, De Carli M, D'Elios MM, Maestrelli P, Ricci M, Fabbri L, et al: Allergen exposure induces the activation of allergen-specific Th2 cells in the airway mucosa of patients with allergic respiratory disorders. Eur J Immunol 1993, 23:1445-1449.

8. Robinson DS, Hamid Q, Ying S, Tsicopoulos A, Barkans J, Bentley AM, et al: Predominant TH2-like bronchoalveolar T-lymphocyte population in atopic asthma. N Engl J Med 1992, 326:298-304.

9. Van Wetering S, Zuyderduyn S, Ninaber DK, van Sterkenburg MA, Rabe KF, Hiemstra PS: Epithelial differentiation is a determinant in the production of eotaxin- 2 and -3 by bronchial epithelial cells in response to IL-4 and IL-13. Mol Immunol 2007, 44:803-811.

10. Zhu Z, Homer RJ, Wang Z, Chen Q, Geba GP, Wang J, et al: Pulmonary expression of interleukin-13 causes inflammation, mucus hypersecretion, subepithelial fibrosis, physiologic abnormalities, and eotaxin production. J Clin Invest 1999, 103:779-788.

11. Laoukili J, Perret E, Willems T, Minty A, Parthoens E, Houcine O, et al: IL-13 alters mucociliary differentiation and ciliary beating of human respiratory epithelial cells. J Clin Invest 2001, 108:1817-1824.

12. Yoshisue H, Puddicombe SM, Wilson SJ, Haitchi HM, Powell RM, Wilson DI, et al: Characterization of ciliated bronchial epithelium 1, a ciliated cellassociated gene induced during mucociliary differentiation. Am J Respir Cell Mol Biol 2004, 31:491-500.

13. Atherton HC, Jones G, Danahay H: IL-13-induced changes in the goblet cell density of human bronchial epithelial cell cultures: MAP kinase and phosphatidylinositol 3-kinase regulation. Am J Physiol Lung Cell Mol Physiol 2003, 285:L730-L739.
14. Ong PY, Ohtake T, Brandt C, Strickland I, Boguniewicz M, Ganz T, et al: Endogenous antimicrobial peptides and skin infections in atopic dermatitis. N Engl J Med 2002, 347:1151-1160.

15. Nomura I, Goleva E, Howell MD, Hamid QA, Ong PY, Hall CF, et al: Cytokine milieu of atopic dermatitis, as compared to psoriasis, skin prevents induction of innate immune response genes. J Immunol 2003, 171:3262-3269.

16. Albanesi C, Fairchild HR, Madonna S, Scarponi C, De Pita O, Leung DY, et al: IL-4 and IL-13 negatively regulate TNF-alpha- and IFN-gamma-induced beta-defensin expression through STAT-6, suppressor of cytokine signaling (SOCS)-1, and SOCS-3. J Immunol 2007, 179:984-992.

17. Howell MD, Gallo RL, Boguniewicz M, Jones JF, Wong C, Streib JE, et al: Cytokine milieu of atopic dermatitis skin subverts the innate immune response to vaccinia virus. Immunity 2006, 24:341-348.

18. Beisswenger C, Kandler $K$, Hess C, Garn H, Felgentreff $K$, Wegmann M, et al: Allergic airway inflammation inhibits pulmonary antibacterial host defense. J Immunol 2006, 177:1833-1837.

19. Van Wetering $S$, van der Linden AC, van Sterkenburg MA, Rabe KF, Schalkwijk J, Hiemstra PS: Regulation of secretory leukocyte proteinase inhibitor (SLPI) production by human bronchial epithelial cells: increase of cell-associated SLPI by neutrophil elastase. J Investig Med 2000, 48:359-366.

20. Tjabringa GS, Vos JB, Olthuis D, Ninaber DK, Rabe KF, Schalkwijk J, et al: Host defense effector molecules in mucosal secretions. FEMS Immunol Med Microbiol 2005, 45:151-158.

21. Wingens $M$, van Bergen BH, Hiemstra PS, Meis JF, Vlijmen-Willems IM, Zeeuwen PL, et al: Induction of SLPI (ALP/HUSI-I) in epidermal keratinocytes. J Invest Dermatol 1998, 111:996-1002.

22. Proud $D$, Sanders SP, Wiehler $S$ : Human rhinovirus infection induces airway epithelial cell production of human beta-defensin 2 both in vitro and in vivo. I Immunol 2004, 172:4637-4645.

23. Diamond G, Yim S, Rigo I, McMahon L: Measuring antimicrobial peptide activity on epithelial surfaces in cell culture. Methods Mol Biol 2010, 618:371-382.

24. Murakami M, Lopez-Garcia B, Braff M, Dorschner RA, Gallo RL: Postsecretory processing generates multiple cathelicidins for enhanced topical antimicrobial defense. J Immunol 2004, 172:3070-3077.

25. Peyret-Lacombe A, Duplan H, Watts M, Charveron M, Brunel G: Antimicrobial peptide modulation in a differentiated reconstructed gingival epithelium. Cell Tissue Res 2007, 328:85-95.

26. Hase K, Eckmann L, Leopard JD, Varki N, Kagnoff MF: Cell differentiation is a key determinant of cathelicidin LL-37/human cationic antimicrobial protein 18 expression by human colon epithelium. Infect Immun 2002, 70:953-963.

27. Kikuchi T, Shively JD, Foley JS, Drazen JM, Tschumperlin DJ: Differentiation-dependent responsiveness of bronchial epithelial cells to IL-4/13 stimulation. Am J Physiol Lung Cell Mol Physiol 2004, 287: L119-L126.

28. Singh PK, Tack BF, McCray PB, Welsh MJ: Synergistic and additive killing by antimicrobial factors found in human airway surface liquid. Am J Physiol Lung Cell Mol Physiol 2000, 279:L799-L805.

29. Harder J, Meyer-Hoffert U, Teran LM, Schwichtenberg L, Bartels J, Maune S, et al: Mucoid Pseudomonas aeruginosa, TNF-alpha, and IL-1beta, but Not IL-6, Induce Human beta -Defensin-2 in Respiratory Epithelia. Am J Respir Cell Mol Biol 2000, 22:714-721.

30. Bals R, Wang X, Zasloff M, Wilson JM: The peptide antibiotic LL-37/hCAP18 is expressed in epithelia of the human lung where it has broad antimicrobial activity at the airway surface. Proc Natl Acad Sci USA 1998, 95:9541-9546.

31. Gray TE, Guzman K, Davis CW, Abdullah LH, Nettesheim P: Mucociliary differentiation of serially passaged normal human tracheobronchial epithelial cells. Am J Respir Cell Mol Biol 1996, 14:104-112.

32. Vermeer PD, Harson R, Einwalter LA, Moninger T, Zabner J: Interleukin-9 induces goblet cell hyperplasia during repair of human airway epithelia. Am J Respir Cell Mol Biol 2003, 28:286-295.

33. Felgentreff $K$, Beisswenger C, Griese M, Gulder T, Bringmann G, Bals R: The antimicrobial peptide cathelicidin interacts with airway mucus. Peptides 2006, 27:3100-3106.

34. Bucki R, Byfield FJ, Janmey PA: Release of the antimicrobial peptide LL-37 from DNA/F-actin bundles in cystic fibrosis sputum. Eur Respir J 2007, 29:624-632. 
35. Davidson DJ, Currie AJ, Reid GS, Bowdish DM, MacDonald KL, Ma RC, et al: The cationic antimicrobial peptide LL-37 modulates dendritic cell differentiation and dendritic cell-induced T cell polarization. J Immunol 2004, 172:1146-1156.

doi:10.1186/1465-9921-12-59

Cite this article as: Zuyderduyn et al:: IL-4 and IL-13 exposure during mucociliary differentiation of bronchial epithelial cells increases antimicrobial activity and expression of antimicrobial peptides. Respiratory Research 2011 12:59.

Submit your next manuscript to BioMed Central and take full advantage of:

- Convenient online submission

- Thorough peer review

- No space constraints or color figure charges

- Immediate publication on acceptance

- Inclusion in PubMed, CAS, Scopus and Google Scholar

- Research which is freely available for redistribution

Submit your manuscript at www.biomedcentral.com/submit
() Biomed Central 